\title{
Comparison of Web Based and PWA in Online Learning
}

\author{
Dian Nugraha $^{1, *}$ Febria Anjara ${ }^{2}$, Safira Faizah ${ }^{1}$ \\ ${ }^{1}$ Faculty Engineering \& Computer Science, Jakarta Global University, West Java-Indonesia \\ ${ }^{2}$ Faculty Economy \& Business, Jakarta Global University, West Java-Indonesia \\ *Corresponding author. Email: dian.nugrahatca@gmail.com
}

\begin{abstract}
In this study, the author intends to improve online learning media (E-Learning) which is widely used by all educational institutions in Indonesia and even throughout the world. Progressive Web Application (PWA) itself is the ability of an application to have features such as web-based applications in general, but with mobile experience optimization in its use. One of these features utilizes the cache from the browser that was previously accessed so that it can save on data consumption during the implementation of learning and maximize the online test process. It is hoped that this research can maximize online learning and anticipate obstacles when students carry out online learning. For the test, the author compares the web application using PWA which will be built with the learning media used by Jakarta Global University which is based on Moodle. From the results of the tests that we carried out, it was found that the results of this optimization there were improvements in terms of Performance, Accessibility, Best Practice, SEO and PWA. Collected data from Lighthouse has shown that J-Lens has significant result compared to JGU Learning. Average J-Lens has a score of 26,8\% more than JGU Learning for each score of JGU Learning 57,6\% and j-Lens 84,4\% for this measurement. Implementing PWA on j-lens applications, this allows users to install this application with smaller memory compared to mobile-based applications.
\end{abstract}

Keywords: E-learning, PWA, Optimization, Improvement.

\section{INTRODUCTION}

The use of technology is growing along with the number of users. One of the things that makes it easier is the use of mobile devices that relate to various kinds of web access and application access. Initially the development of web technology was introduced in 1990 with a static web 1.0 version to become a web application that can handle the problem of checking battery status, using offline mode and speech recognition. As for access to the application itself, in its development it is divided into native applications and web applications. Native applications have fast performance, can send push notifications, have an icon to open the application, and have an easy-to-understand interface but the costs required to build and maintain are not cheap. For web applications, users are asked to open via a browser (on a laptop or smartphone). Sooner or later a web application becomes a challenge in its development [1]-[3].

To overcome these developments, according to [3], Google created a new technology that is becoming the center of attention in the use of technology, namely Progressive Web App (PWA). PWA is one of the advanced methods in software development by combining native applications, web applications, and desktops using the most up-to-date technology by utilizing modern browser features so that it looks as if it is a native application described as a collection of technologies, design concepts and concepts. This PWA itself has been used by several large companies such as AliExpress, BookMyShow, Forbes, Pinterest, Flipkart and so on [4]. This proves that the use of PWA is very convincing to be developed for other segments. In this case, the author will apply this feature to optimize online learning media using PWA with the aim that the learning process can be optimized [2], [5]. The main purpose of the emergence of e-learning is to encourage change in the world of education by prioritizing dominant, independent and interactive participation to improve learning outcomes, but what often becomes an obstacle is the availability of an e-learning platform that meets needs and is stable even in minimal internet connection or offline conditions [6]. Based on the description above, this research is intended to test the performance of using PWA compared to elearning that use websites frameworks. 


\section{LITERATURE REVIEW}

\subsection{E-Learning}

E-Learning is an online education method that can include all methods used in learning through the internet. There are several aspects that must be considered when we design an E-Learning following quality standards in the world of education such as planning, implementing, and evaluating learning [7]. The main purpose of the emergence of e-learning, is to encourage change in the world of education by prioritizing dominant, independent, and interactive participation to improve learning outcomes [6].

By utilizing E-learning there are several advantages that we can get as educators in terms of Flexibility, Independence and Efficiency. What is meant by being flexible is in choosing the time and place to access learning. To be independent means to be able to provide opportunities for learners to independently control the success of learning. While efficiency here can be interpreted as cost efficiency for the administration of the organizers, the efficiency of providing physical facilities and facilities for learning, from the student's perspective is in terms of transportation and accommodation.

\subsection{Progressive Web Application (PWA)}

Application development using PWA has been widely carried out and published until now. This is done because there is still a need to improve the quality of applications and user experience in line with the rapid development of technology to date. PWA itself is not a new thing to learn and apply, considering that several large companies such as Alibaba Express have used this technology first. Because this technology allows us to produce applications that can be accessed like native applications, can read devices, can run offline and can also be accessed via a browser only which allows a wider reach [8].

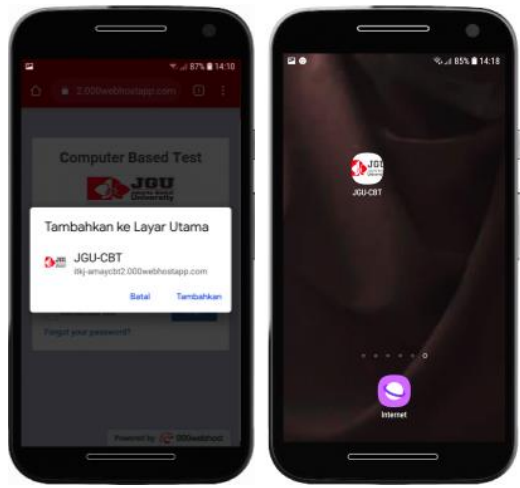

Figure 1. Installed Web application Shortcut on the Smartphone

The concept of using PWA has the main characteristics of being reliable, fast, and engaging, so that users get the best experience in using a web application (Adi et al., 2018). On the other hand, conventional mobile application development requires development which is quite costly in its implementation and requires more resources. In this e-learning development, the author takes advantage of one of the features in PWA that can be run on all devices, both desktop and mobile. This feature also allows users to install this application on their respective smartphones with a smaller capacity compared to mobile applications, and users will also get notifications just like on mobile apps [9].

\subsection{Lighthouse}

Lighthouse is an open-source resource for web developer, automated tool for improving the quality of web pages. The design of the study object that will be evaluated in each application is related to the elements of Performance, Accessibility, Best Practice, SEO and PWA by using the lighthouse on devTools which is a default feature of Google Chrome as a testing tool. Tests using this lighthouse can be set as shown in Figure 2 below.

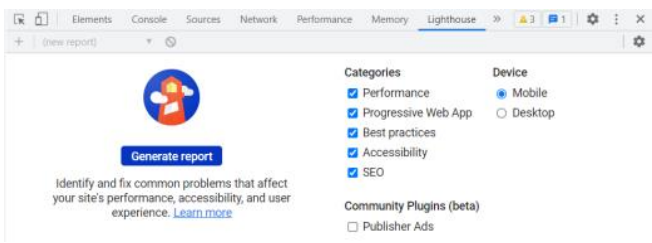

Figure 2. Lighouse in Chrome DevTools

\subsection{Related Works}

As we explained earlier, this PWA has been widely used by various large agencies to improve user experience because of its reliability. However, not many have focused on implementing this application in the world of education.

Riady in 2019, [10] has developed this application into a spiritual e-learning for the needs of the Christian Congregation to share seminar content and lectures in church. In his paper, he has stated that the application using PWA has a good advantage, especially in terms of response when the connection is bad, even when offline. The results of the comparison can be seen in table 1 . However, on this web application there is still no known method for assessing learning outcomes that can measure learning progress, learning outcomes and detect learning outcomes on an ongoing basis.

Table 1. Comparison of PWA and Reguler Websites

\begin{tabular}{|l|c|l|}
\hline Indicator & PWA & $\begin{array}{l}\text { Native Web } \\
\text { App }\end{array}$ \\
\hline Homepage & 99 & 100 \\
\hline
\end{tabular}




\begin{tabular}{|l|c|c|}
\hline Login page & 100 & 100 \\
\hline Register page & 99 & 100 \\
\hline Profile & 100 & 100 \\
\hline $\begin{array}{l}\text { Average Performance } \\
\text { (Lighthouse) }\end{array}$ & 99.5 & 100 \\
\hline
\end{tabular}

The same thing has also been proven by Ruslianto in 2019 [11], apply this PWA to vehicle surveillance at the Malaysia-Indonesia border. In their writings, they have also proven efficient use of memory with a total cache of $650 \mathrm{~kb}, 2 \mathrm{~kb}$ for service workers and $302 \mathrm{~kb}$ for indexDB and a maximum bandwidth usage of $1.3 \mathrm{MBps}$. With the tests carried out by the two authors, it has been proven that this PWA can not only be accessed in a weak internet network. But it can also save device memory and save internet quota during operation.

\section{METHODOLOGY}

The creation of this e-learning application includes sharing of materials and formative/summative tests that are carried out and combined with the Progressive Web App. In other words, this application allows users to access quickly with just an application and display the mobile web on a smartphone device.

In this study the authors use the AGILE methodology.

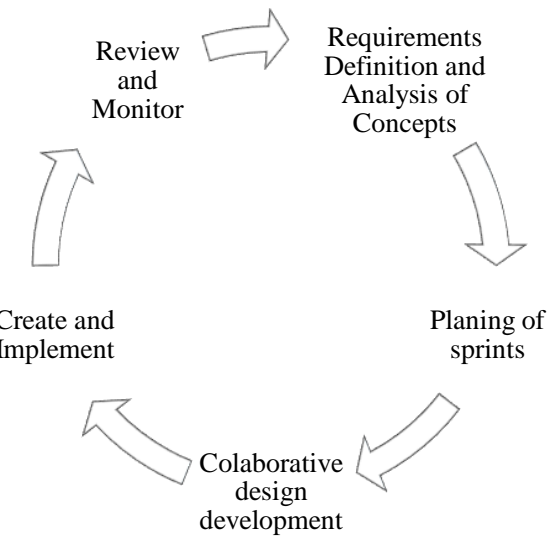

Figure 3. Agile Methodology

This methodology consists of:

a. Requirements Definition and Analysis of Concepts: determine the current state of the project and what is to be achieved.

b. Planning of sprints: collect resources needed to optimize the work process.

c. Collaborative design development: integrating the initiation process to the feedback process.

d. Create and Implement: frequent development delivery through the sprint, Feedback on testing and appropriate changes are imperative.

e. Review and Monitor: make sure the metric is meet with the objective of the research.

The application access start with the choices between login or register. If the user already has an account, directly they can insert the username and password and choose the access they will be. There are three access users, admin to manage account, lecture to create course including the curriculum, lecture profile, course description, quiz etc. Students have access to join courses, create my courses, join quizzes, assessments, and others. If the user doesn't have an account, they should do register and fulfil the form.

The flowchart for PWA-based application access is as follows:

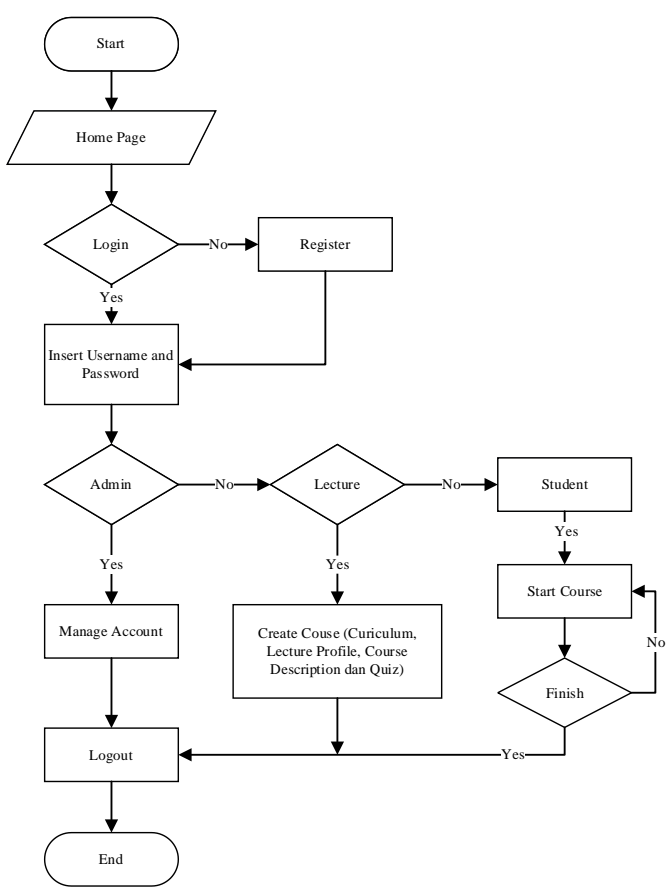

Figure 4. Flowchart Application

\section{RESULT AND DISCUSSION}

Since the application has been developed using PWA, the application is working better than native application in term of speed, flexibility, and ease of use. Screenshot for $\mathrm{j}$-Lens can be seen in figure 3 below.

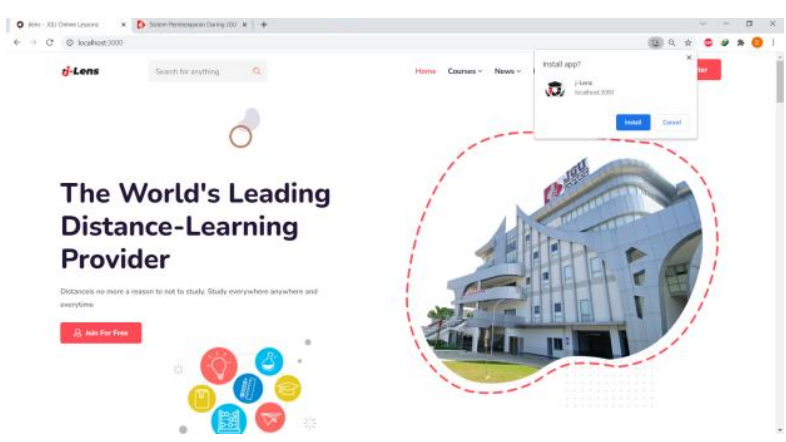

Figure 5. Screenshot j-Lens

The next stage after completing e-learning using PWA is the testing stage to obtain measurements of various aspects that have been improved from several previous applications and research. There are two types of tests carried out in this study: 
a. Test Variables

During this research, we tested two native and PWAbased applications using several variables including Performance, Accessibility, Best Practice, SEO and PWA. Also, we consider to measure our web application in terms of loading speed and website performance monitor using some variables like DOMContentLoad, FLT (fully loaded time), TPS (total page site) and request.

b. Test scenario

This is related to using the test variables above in the form of application performance to get test results in the form of percent, second and unit of file size.

\subsection{Result of Testing}

The test results using lighthouse developer tools to get measurements in terms of Performance, Accessibility, Best Practice, SEO and PWA can be seen in Figure 5 and table 2 below:

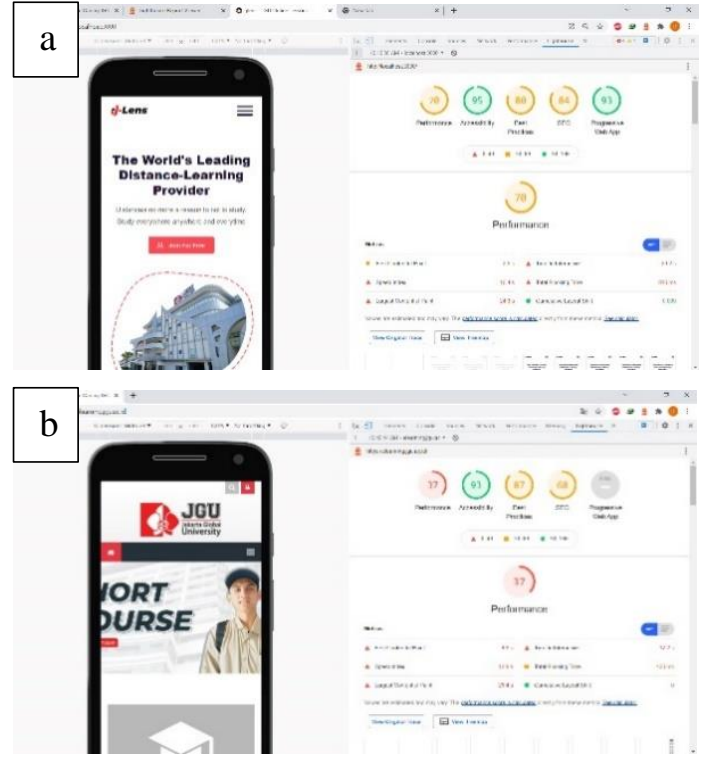

Figure 6. Lighthouse Application Audit for (a) J-Lens and (b) JGU Learning

Table 2. Comparison site performs JGU Learning and JLens

\begin{tabular}{|c|c|c|c|c|c|}
\hline App & $\begin{array}{l}\text { Perfor } \\
\text { mance }\end{array}$ & $\begin{array}{l}\text { Access } \\
\text { ibility }\end{array}$ & $\begin{array}{l}\text { Best } \\
\text { Prac } \\
\text { tice }\end{array}$ & ${ }^{1}$ SEO & ${ }^{2} \mathbf{P W A}$ \\
\hline $\begin{array}{l}\text { JGU learning } \\
\text { (Native app) }\end{array}$ & 40 & 93 & 87 & 68 & 0 \\
\hline $\begin{array}{l}\text { J-Lens (PWA } \\
\text { Based app) }\end{array}$ & 70 & 95 & 80 & 84 & 93 \\
\hline
\end{tabular}

From data above we can conclude if J-Lens has significant result compared to JGU Learning. Average JLens has 26,8\% more score than JGU Learning for each score of JGU Learning $57,6 \%$ and $\mathrm{j}$-Lens $84,4 \%$ for this measurement. Implement PWA to j-Lens it could be installed to every device in small memory compared to mobile app. Meanwhile The results of application testing based on loading speed and website performance monitor to find out how effective and efficient the $\mathrm{j}$-Lens application is compared to existing applications can be seen in table 3 below.

Table 3. Comparison site performs JGU Learning and JLens

\begin{tabular}{|l|c|c|c|c|}
\hline App & DCL & $\begin{array}{l}\text { Fully } \\
\text { Loaded } \\
\text { Time }\end{array}$ & $\begin{array}{l}\text { Total } \\
\text { Page } \\
\text { Site }\end{array}$ & Request \\
\hline $\begin{array}{l}\text { JGUlearning } \\
\text { (Native app) }\end{array}$ & $1.30 \mathrm{~s}$ & $1.5 \mathrm{~ms}$ & $7.1 \mathrm{mb}$ & 40 \\
\hline $\begin{array}{l}\text { J-Lens (PWA } \\
\text { Based app) }\end{array}$ & $860 \mathrm{~ms}$ & $1.15 \mathrm{~ms}$ & $24.8 \mathrm{mb}$ & 105 \\
\hline
\end{tabular}

From the table above, the performance of the $\mathrm{j}$-Lens is more optimal compared to the JGU Learning application. Although the request and the total page site on $\mathrm{j}$-Lens are larger, the fully load and DOMContentLoad generated are shorter, this is because the optimization of the single page application and PWA on $\mathrm{j}$-Lens has been running very well.

\section{CONCLUSION}

Based on the testing and analysis that has been done, the researcher has drawn some conclusions as follows:

1. Improving performance and e-learning features using PWA, this can result in more reliable applications. PWA has service workers who oversee managing website asset cache efficiently. As a result, the application runs quickly thereby increasing user comfort. It is proven by the results in testing phase using lighthouse which shows that PWA-based applications are $26.8 \%$ more than the Native Applications. The maximum score on this application is $84.4 \%$ with a performance index of $70 \%$.

2. Testing using loading speed and website performance monitor to measure how fast the $\mathrm{j}$-Lens application is accessed. With more than twice the request than a regular web application but can produce a shorter FLT. This is because of the cache and service workers, $\mathrm{j}$-Lens runs "seamless" like a native app and saves data like a regular website. As a result, if we open the same page 2 times, the data will be used only 1 time. The data used is the data when loading the page for the first time.

3. This app working on devices of any form factor and offers a native-like experience without duplicating the development effort to run on different operating 
systems and platforms. Applications that use PWA can be accessed without having to install the application. Just open a browser, navigate to the PWA application URL, and then use it like a native app. Because the application only places a shortcut from this application to the home screen, when the shortcut is opened, the appearance of this application will be like the application that we install on the Play store or Apple Store.

\section{AUTHORS' CONTRIBUTIONS}

The authors contributions to create education and improve the development of e-Learning for the convenience of the learning process while online learning is still ongoing by providing solutions related to the development of information technology.

\section{ACKNOWLEDGMENTS}

The authors would like to acknowledge the support from Jakarta Global University throughout this project. This project has been funded by the Ministry of Education and Culture under the scheme of Research of Early Career Lecturer (PDP) No. B/112/E3/RA.00/2021.

\section{REFERENCES}

[1] A. Kurniawan, I. S. Areni, and A. Achmad, "Implementasi Progressive Web Application pada Sistem Monitoring Keluhan Sampah Kota Makassar," J. Penelit. Enj., vol. 21, no. 2, pp. 3438, 2018, doi: 10.25042/jpe.112017.05.

[2] M. R. Ridho, A. Pinandito, and R. K. Dewi, "Perbandingan Performa Progressive Web Apps dan Mobile Web Terkait Waktu Respon , Penggunaan Memori dan Penggunaan Media Penyimpanan," J. Pengemb. Teknol. Inf. dan Ilmu Komput., vol. 2, no. 10, pp. 3483-3491, 2018.

[3] A. A. Kurniawan, "Analisis Performa
Progressive Web Application (Pwa) Pada Perangkat Mobile," J. Ilm. Inform. Komput., vol. 25 , no. 1 , pp. 18-31, 2020, doi: 10.35760/ik.2020.v25i1.2510.

[4] K. Behl and G. Raj, "Architectural Pattern of Progressive Web and Background Synchronization," Proc. 2018 Int. Conf. Adv. Comput. Commun. Eng. ICACCE 2018, no. June, pp. 366-371, 2018, doi: 10.1109/ICACCE.2018.8441701.

[5] R. S. Mishra, "Progressive WEBAPP : Review," Int. Res. J. Eng. Technol., vol. 3, no. 6, pp. 30283032, 2016

[6] N. Harrati, I. Bouchrika, A. Tari, and A. Ladjailia, "Exploring user satisfaction for elearning systems via usage-based metrics and system usability scale analysis," Comput. Human Behav., vol. 61, pp. 463-471, 2016, doi: 10.1016/j.chb.2016.03.051.

[7] E. P. I. H. Baroya, "Strategi Pembelajaran Abad 21 - Lpmp Jogja," J. Lemb. Penjaminan Mutu Pendidik. Prov. DIYogyakarta, vol. I, no. 01, pp. 101-115, 2018.

[8] A. Biørn-Hansen, T. A. Majchrzak, and T. M. Grønli, "Progressive web apps: The possibleweb-native unifier for mobile development," WEBIST 2017 - Proc. 13th Int. Conf. Web Inf. Syst. Technol., pp. 344-351, 2017, doi: 10.5220/0006353703440351.

[9] L. Adi, R. J. Akbar, and W. N. Khotimah, "Platform e-Learning untuk Pembelajaran Pemrograman Web Menggunakan Konsep Progressive Web Apps," J. Tek. ITS, vol. 6, no. 2, 2018, doi: 10.12962/j23373539.v6i2.24291.

[10] J. Riady, H. N. Palit, J. Andjarwirawan, and Petra, "Aplikasi E-Learning Berbasis Progressive Web App Pada Apologetika Indonesia," J. Infra Petra, pp. 1-5, 2019.

[11] U. R. Ikhwan Ruslianto, “JURNAL RESTI,” vol. 3, 2019. 